\title{
Robust pH-responsive group IV metal oxide functionalized porous silicon platforms
}

Joel F. Destino, ${ }^{a}$ Nadine D. Kraut,,${ }^{b}$ Lara E. Hargrave, ${ }^{a}$ and Frank V. Bright ${ }^{a *}$

a. Department of Chemistry, Natural Sciences Complex, University at Buffalo, The State University of New York, Buffalo, NY 14260-3000, United States

b. PPG Industries Inc., 440 College Park Dr., Monroeville, PA 15146, United States

\begin{abstract}
We report a high stability $\mathrm{pH}$-responsive sensor based on group IV metal oxide $\left(\mathrm{ZrO}_{2}\right.$ and $\left.\mathrm{HfO}_{2}\right)$ functionalized porous silicon ( $\mathrm{pSi}$ ). These hybrid metal oxide-pSi (MOx-pSi) materials were tested during repeated $\mathrm{pH} 2-12$ cycling and during continuous UV illumination. The photoluminescence $(\mathrm{PL})$ response proved to be fully reversible unlike uncoated pSi. The MOxpSi sensor platform was also stable for at least three years.
\end{abstract}

\section{Keywords}

Hafnia; Luminescence; pH Sensor; Porous silicon; Sol-gel processing; Zirconia

\section{Introduction}

As prepared, $\mathrm{H}$-passivated $\mathrm{pSi}$ (ap-pSi) undergoes rapid oxidation in air [1] or water [2] in the absence/presence of photons [3, 4] to form oxidized pSi (ox-pSi). ox-pSi PL is dramatically different in comparison to ap-pSi [1,5-7] and it undergoes rapid dissolution under acidic/basic conditions [8-11]. Given this, researchers have aimed at modify pSi by using hydrosilylation [12-16], silanization [17-21], and physisorbed coatings [12, 22] to minimize and ideally eliminate the aforementioned problems. Unfortunately, there are few reports on $\mathrm{pSi}$ passivation that demonstrate improved stability across wide $\mathrm{pH}$ ranges and constant illumination as one would encounter in chemical sensing applications [23].

Group IV metal oxides (e.g., $\mathrm{TiO}_{2}, \mathrm{ZrO}_{2}$ and $\mathrm{HfO}_{2}$ ) are unique materials with wide applicability (e.g., free-standing [24] and supported [25] catalysts, semiconductor gate dielectrics [26, 27], field-effect transistors [28, 29], and chromatographic stationary phases [30, 31]). $\mathrm{ZrO}_{2-}$ and $\mathrm{HfO}_{2}$-based materials are attractive because they are known to exhibit improved $\mathrm{pH}$ and thermal stability [32-34] in comparison to $\mathrm{SiO}_{2}$. Further, $\mathrm{Zr}$ - and $\mathrm{HfO}_{2}$ can be easily prepared by sol-gel processing [11], they cross-link to $\mathrm{SiOH}$ residues [35, 36], and ox-pSi has surface $\mathrm{SiOH}$ residues [37].

Page 1 of 8 
Herein we report $\mathrm{ZrO}_{2}$ and $\mathrm{HfO}_{2}$ functionalized ox-pSi for optically-based $\mathrm{pH}$ sensing. These materials were studied by using scanning electron microscopy (SEM), energy dispersive X-ray spectroscopy (EDS), and Fourier transform infrared (FTIR) spectroscopy. pH-dependent response and photostability experiments were conducted by using steady state PL emission measurements.

\section{Materials and methods}

2.1. Materials. The following were used: p-type B-doped $<100>C Z$ processed $8-12 \Omega \cdot \mathrm{cm} \mathrm{Si}$ wafers (Alsil Supply Division, Y Mart Int.); HF (48-51\%) (Acros); 200 proof ethanol (Decon Laboratories); pentanes (99.7\%) (Fisher Scientific); Ga/ln eutectic (99.99\%), $\mathrm{HfCl}_{4}(99.95 \%)$ and $\mathrm{ZrCl}_{4}$ (99.95\%) (Sigma Aldrich); $\mathrm{NaOH}$ pellets (Mallinckrodt); and 37\% $\mathrm{HCl}$ (EMD). Deionized $\mathrm{H}_{2} \mathrm{O}(\geq 18 \mathrm{M} \Omega \mathrm{cm}$ ) was produced by a $50 \mathrm{k}$ light Silex deionizer (AmeriWater).

2.2. MOx-pSi Fabrication. The MOx-pSi fabrication scheme is presented in Fig. 1. Briefly, appSi and ox-pSi were prepared as described elsewhere [16, 37]. MOx sols were prepared from their chloride salts (30 $\mathrm{mM} \mathrm{ZrCl}_{4}$ or $\mathrm{HfCl}_{4}$ in 1:9 (vol:vol) $\mathrm{H}_{2} \mathrm{O}: \mathrm{EtOH}$ ). The ox-pSi surface was functionalized with $\mathrm{Zr}$ - or $\mathrm{HfO}_{2}$ by spin coating two consecutive $100 \mu \mathrm{L}$ sol aliquots at $150 \mathrm{RPM}$ followed by $30 \mathrm{~s}$ at $1000 \mathrm{RPM}$. The reaction was completed by heating for $30 \mathrm{~min}$ at $300{ }^{\circ} \mathrm{C}$ and natural cooling to room temperature. (Note: Temperatures up to $700{ }^{\circ} \mathrm{C}$ were explored; $300{ }^{\circ} \mathrm{C}$ was selected because it yielded good PL while bonding MOx to the ox-pSi.)

2.3. Characterization. SEM micrographs were recorded by using a Hitachi model SU-70 equipped with EDS. Reflectance FTIR spectra were measured by using a Bruker Vertex 70 with Hyperion 3000 microscope attachment $\left(4 \mathrm{~cm}^{-1}\right.$ resolution, 200 scans, 15x, ox-pSi blank). PL emission spectra were acquired by using an SLM-AMINCO 8100 spectrofluorometer $\left(\lambda_{\mathrm{ex}}=325\right.$ $\pm 4 \mathrm{~nm}$ ). Photostability was determined while monitoring the total PL (500-800 nm).

2.4. $\mathrm{pH}$-dependent experiments. Aqueous $\mathrm{pH}$ solutions $(10 \mathrm{mM})$ were prepared from $\mathrm{HCl}$ and $\mathrm{NaOH}$. Solution $\mathrm{pH}$ values were determined by using a calibrated $\mathrm{pH}$ electrode/meter. The MOx-pSi samples were mounted in a custom flow cell with a quartz viewing window. $A$ peristaltic pump served to flow solutions over the samples. The $\mathrm{pH}$ responses were determined by measuring the MOx-pSi PL-dependent signal during a rapid change in solution $\mathrm{pH}$. The response time $\left(t_{90}\right)$ is reported as the time to reach $90 \%$ of the full response.

2.5. Statistical analysis. Results are reported as the mean and measurement standard deviation. Statistical significance is assessed by using analysis of variance (ANOVA) (95\% confidence level) with $p$ be $\leq 0.05$ being statistically significant. 


\section{Results and discussion}

Fig. 1 shows that the MOx-pSi hybrid materials exhibit strong PL in comparison to oxpSi after pH cycling (compare PL images in Fig. 1a and Fig. 1b); ox-pSi undergoes complete dissolution (Fig. 1b) during our experiments and it is unsuitable for pH sensing. Fig. 2 presents typical SEM, EDS, and FTIR data for our MOx-pSi platforms. Figs. $\mathbf{2 a}$ and $\mathbf{2 d}$ show that the MOX-pSi platform is characterized by a $\sim 200 \mathrm{~nm}$ thick ox-pSi layer atop a crystalline $\mathrm{Si}$ (c-Si) base. Figs. $2 \mathbf{b}$ and $2 \mathrm{e}$ present $\mathrm{ZrO}_{2}$ - and $\mathrm{HfO}_{2}$-pSi EDS spectra, confirming the presence of $\mathrm{Zr}$ and $\mathrm{Hf}$, respectively. Figs. $2 \mathrm{c}$ and $2 \mathrm{f}$ present $\mathrm{ZrO}_{2}$ - and $\mathrm{HfO}_{2}-\mathrm{pSi} \mathrm{FTIR}$ spectra, respectively [38]. The $\mathrm{ZrO}_{2}$ - and $\mathrm{HfO}_{2}$-pSi IR spectra are characterized by a Zr-O-Si stretching band at 947 $\mathrm{cm}^{-1}$ (highlighted, Fig. 2c) and a Hf-O-Si stretching band at $962 \mathrm{~cm}^{-1}$ (highlighted, Fig. 2f) [39, 40]; confirming $\mathrm{Zr}-/ \mathrm{HfO}_{2}$ is covalently bonded to the ox-pSi. The lower frequency IR bands are commonly observed in mixed $\mathrm{Zr} / \mathrm{HfO}_{2}-\mathrm{SiO}_{2}$ materials and are associated with various $\mathrm{M}-\mathrm{O}-\mathrm{Si}$ geometries [35, 41].

Figs. 3 and $\mathbf{4}$ present typical $\mathrm{pH}$-dependent $\mathrm{PL}$ emission spectra (a) and average $\mathrm{PL}$ and emission maximum $\left(\lambda_{e m, m a x}\right)$ response profiles ( $\mathbf{b}$ and $\mathbf{c}$ ) for $\mathrm{ZrO}_{2}-$ and $\mathrm{HfO}_{2}-\mathrm{pSi}$, respectively. Inspection of these results reveals several key points. First, the $\mathrm{ZrO}_{2}$ - and $\mathrm{HfO}_{2^{-}}$ based materials behave similarly. Second, as the $\mathrm{pH}$ increases the MOx-pSi PL intensity decreases and the $\lambda_{e m, \max }$ blue shifts systematically. These changes are consistent with the pSi $\mathrm{PL}$ emission arising from $\mathrm{Si}$ nanocrystallites composed of $\mathrm{Si}, \mathrm{SiO}_{x}$, and $\mathrm{SiO}_{2}$ (red, green, and blue emission bands, respectively) [42-44] coupled with $\mathrm{pH}$-dependent dangling bond formation following proton extraction $[8,45]$.

Third, the MOx-pSi pH-dependent PL responses are linear over the entire $\mathrm{pH}$ range studied. $\mathrm{HfO}_{2}-\mathrm{pSi}$ shows slightly improved sensitivity over $\mathrm{ZrO}_{2}-\mathrm{pSi}$ based on $\mathrm{PL}$ intensity $(-0.18$ \pm 0.02 vs. $-0.12 \pm 0.01 \mathrm{PL} / \mathrm{pH}$ unit, $p=0.01)$ and $\lambda_{e m, \max }(-3.9 \pm 0.4$ vs. $-3.3 \pm 0.3 \mathrm{~nm} / \mathrm{pH}$ unit, $p=$ $0.11)$ responses. The observed linear response is consistent with the complex MOx surface chemistry revealed by our IR measurements (Figs. 2c and 2f) and hydroxyl groups with $p K_{a}$ values ranging from 4 to 13 [34]. This scenario likely creates a pH buffer layer at the pSi surface [34], attenuating the impact on the pSi PL across large pH changes. Fourth, the MOx-pSi pHdependent PL intensity response is only quasi-reversible; the response sensitivity systematically increases by $\sim 2$-fold with increasing cycle number $(p<0.001)$. Finally, the $\mathrm{pH}$-dependent $\lambda_{\text {em,max }}$ response profiles are independent of cycle number $(p=0.09-0.13)$ showing a completely reversible response. Taken together these results show that the MOx-pSi- based materials, in a $\lambda_{e m, m a x}$-based measurement format, provide an analytically useful response between $\mathrm{pH} 2$ and 12. 
The MOx-pSi $t_{90}$ values were typically $380 \pm 10 \mathrm{~s}$. However, $t_{90}$ was also etching time $\left(t_{E}\right.$, porosity) [16] and $\mathrm{MCl}_{4}$ concentration dependent. Longer $t_{E}$ yielded significant longer $t_{90}$ (e.g., $t_{E}$ $=60$ and $150 \mathrm{~s}: t_{90}=610 \pm 30 \mathrm{~s}$ and $880 \pm 30 \mathrm{~s}$, respectively $\left.(p<0.001)\right)$. Increased $\mathrm{MCl}_{4}$ also led to longer response times $\left(300 \mathrm{mM}, t_{E}=150 \mathrm{~s}: t_{90}=1220 \pm 70 \mathrm{~s}\right.$, respectively $\left.(p<0.001)\right)$.

In an optical pH sensor stability is also very important. Fig. 5 assesses the ap- and ox$\mathrm{pSi}, \mathrm{ZrO}_{2}$ - and $\mathrm{HfO}_{2}-\mathrm{pSi}$ photostability in air under continuous UV illumination. These results show that no platform offers complete photostability during 90 min of continuous illumination. The ap-pSi, $\mathrm{ZrO}_{2}$ - and $\mathrm{HfO}_{2}$-pSi platforms undergo a decrease in PL intensity over time. The oxpSi sample undergoes a continuous PL intensity increase over time. Of the systems studied here, the $\mathrm{ZrO}_{2}$-pSi platform exhibits the best intensity-based photostability, being 4-fold better in comparison to ap-pSi and $\sim 2$-fold better compared to ox-pSi $(p=0.001)$. Fortunately, the $\lambda_{\text {em,max }}$ response was unaffected by these intensity changes $(p>0.52)$, making it a more robust $\mathrm{pH}$ response measurement.

Finally, long-term stability studies carried out over a three year time period for MOx-pSi samples stored under ambient conditions showed that they are exceedingly stable; 3 year old MOx-pSi samples exhibited statistically equivalent PL spectra and responses in comparison to freshly prepared samples $(n=35, p=0.59)$.

\section{Conclusions}

$\mathrm{ZrO}_{2}$-and $\mathrm{HfO}_{2}$-pSi hybrid materials are easily prepared and their $\mathrm{pH}$-dependent $\lambda_{\text {em,max }}$ response is fully reversible and analytically useful between $\mathrm{pH} 2$ and $12(0.1 \mathrm{pH}$ resolution). By comparison, at $\mathrm{pH}>8$, ap-/ox-pSi undergo complete dissolution in a few minutes. The $\mathrm{ZrO}_{2}-\mathrm{pSi}$ platform also exhibits significantly improved photostability, and is stable under ambient storage for at least three years.

\section{Acknowledgements}

This research is based in part upon work supported by the National Science Foundation under grant number $\mathrm{CHE}-1411435$. Any opinions, findings, and conclusions or recommendations expressed in this material are those of the authors and do not necessarily reflect the views of the funding source. 


\section{Bibliography}

[1] Cerofolini G, Meda L, Mechanisms and kinetics of room-temperature silicon oxidation, J. Non-Cryst. Solids 216 (1997) 140-147.

[2] Deuro RE, Richardson JP, Reynard JM, Caras CA, Bright FV, Parts per million water in gaseous vapor streams dramatically accelerates porous silicon oxidation, J. Phys. Chem. C 116 (2012) 23168-23174.

[3] Kovalev D, Gross E, Diener J, Timoshenko VY, Fujii M, Photodegradation of porous silicon induced by photogenerated singlet oxygen molecules, Appl. Phys. Lett. 85 (2004) 3590-3592.

[4] Kovalev D, Fujii M, Silicon nanocrystals: photosensitizers for oxygen molecules, Adv. Mater. 17 (2005) 2531-2544.

[5] Harper J, Sailor MJ, Photoluminescence quenching and the photochemical oxidation of porous silicon by molecular oxygen, Langmuir 13 (1997) 4652-4658.

[6] Mawhinney DB, Glass JA, Yates JT, FTIR study of the oxidation of porous silicon, J. Phys. Chem. B 101 (1997) 1202-1206.

[7] Elhouichet $H$, Bessaïs B, Ezzaouia $H$, Oueslati M, Changes in photoluminescence behaviour and structure of porous silicon related to preparation conditions and laser irradiation, Thin Solid Films 304 (1997) 358-364.

[8] Chun JK, Bocarsly AB, Cottrell TR, Benziger JB, Yee JC, Proton gated emission from porous silicon, J. Am. Chem. Soc. 115 (1993) 3024-3025.

[9] Kelly MT, Chun JK, Bocarsly AB, General Brönsted acid behavior of porous silicon: a mechanistic evaluation of proton-gated quenching of photoemission from oxide-coated porous silicon, J. Phys. Chem. B 101 (1997) 2702-2708.

[10] Mo Y, Ren A, Mao J, Zhou Z, Yuan H, Du J, et al., Photoluminescence of oxidized porous silicon treated by sodium borohydride aqueous solution, Mater. Lett. 75 (2012) 115-117.

[11] Brinker CJ, Scherer GW. Sol-gel science: the physics and chemistry of sol-gel processing, Academic Press, Boston, 1990.

[12] Buriak JM, Allen MJ, Lewis acid mediated functionalization of porous silicon with substituted alkenes and alkynes, J. Am. Chem. Soc. 120 (1998) 1339-1340.

[13] Tsang CK, Kelly TL, Sailor MJ, Li YY, Highly stable porous silicon-carbon composites as label-free optical biosensors, ACS nano 6 (2012) 10546-10554.

[14] Gao T, Gao J, Sailor MJ, Tuning the response and stability of thin film mesoporous silicon bapor sensors by surface modification, Langmuir 18 (2002) 9953-9957.

[15] Buriak JM, Organometallic chemistry on silicon and germanium surfaces, Chem. Rev. 102 (2002) 1271-1308.

[16] McCall DT, Zhang Y, Hook DJ, Bright FV, Optimizing pin-printed and hydrosilylated microarray spot density on porous silicon platforms, Langmuir 31 (2015) 11370-11377.

[17] Krepker MA, Segal E, Dual-functionalized porous Si/hydrogel hybrid for label-free biosensing of organophosphorus compounds, Anal. Chem. 85 (2013) 7353-7360.

[18] Schoell S, Hoeb M, Sharp I, Steins W, Eickhoff M, Stutzmann M, et al., Functionalization of $6 \mathrm{H}-\mathrm{SiC}$ surfaces with organosilanes, Appl. Phys. Lett. 92 (2008) 153301.

[19] Gaponenko N, Sol-gel derived films in meso-porous matrices: porous silicon, anodic alumina and artificial opals, Synth. Met. 124 (2001) 125-130.

[20] Kraut ND, Brattlie JD, Deuro RE, McGoorty MM, Bright FV, High-throughput screening system for creating and assessing surface-modified porous silicon, Appl. Spectrosc. 66 (2012) 1171-1178.

[21] Meskini O, Tlili A, M'ghaieth R, Jaffrezic-Renault N, Abdelghani A, Silanization of porous silicon surface for ion-sensor applications, Sensor Lett. 7 (2009) 913-916.

[22] Benilov A, Gavrilchenko I, Benilova I, Skryshevsky V, Cabrera M, Influence of pH solution on photoluminescence of porous silicon, Sens. Actuators, A 137 (2007) 345-349. 
[23] Buriak JM, Allen MJ, Photoluminescence of porous silicon surfaces stabilized through Lewis acid mediated hydrosilylation, J. Lumin. 80 (1998) 29-35.

[24] Tomishige K, Ikeda Y, Sakaihori T, Fujimoto K, Catalytic properties and structure of zirconia catalysts for direct synthesis of dimethyl carbonate from methanol and carbon dioxide, J. Catal. 192 (2000) 355-362.

[25] Bamwenda GR, Tsubota S, Nakamura T, Haruta M, The influence of the preparation methods on the catalytic activity of platinum and gold supported on $\mathrm{TiO}_{2}$ for $\mathrm{CO}$ oxidation, Catal. Lett. 44 (1997) 83-87.

[26] Esplandiu M, Patrito E, Macagno V, Characterization of hafnium anodic oxide films: An AC impedance investigation, Electrochim. Acta 40 (1995) 809-815.

[27] Fiorentini V, Gulleri G, Theoretical evaluation of zirconia and hafnia as gate oxides for $\mathrm{Si}$ microelectronics, Phys. Rev. Lett. 89 (2002) 266101.

[28] Capone S, Leo G, Rella R, Siciliano P, Vasanelli L, Alvisi M, et al., Physical characterization of hafnium oxide thin films and their application as gas sensing devices, J. Vac. Sci. Technol., A 16 (1998) 3564-3568.

[29] Brailsford A, Yussouff M, Logothetis E, A first-principles model of the zirconia oxygen sensor, Sens. Actuators, B 44 (1997) 321-326.

[30] Hoth DC, Rivera JG, Colón LA, Metal oxide monolithic columns, J. Chromatogr. A 1079 (2005) 392-396.

[31] Alhooshani K, Kim T-Y, Kabir A, Malik A, Sol-gel approach to in situ creation of high pHresistant surface-bonded organic-inorganic hybrid zirconia coating for capillary microextraction (in-tube SPME), J. Chromatogr. A 1062 (2005) 1-14.

[32] Nawrocki J, Dunlap C, McCormick A, Carr P, Part I. Chromatography using ultra-stable metal oxide-based stationary phases for HPLC, J. Chromatogr. A 1028 (2004) 1-30.

[33] Zhou H, Xu S, Ye M, Feng S, Pan C, Jiang X, et al., Zirconium phosphonate-modified porous silicon for highly specific capture of phosphopeptides and MALDI-TOF MS analysis, J. Proteome Res. 5 (2006) 2431-2437.

[34] Nawrocki J, Rigney M, McCormick A, Carr PW, Chemistry of zirconia and its use in chromatography, J. Chromatogr. A 657 (1993) 229-282.

[35] del Monte F, Larsen W, Mackenzie JD, Stabilization of tetragonal $\mathrm{ZrO}_{2}$ in $\mathrm{ZrO}_{2}-\mathrm{SiO}_{2}$ binary oxides, J. Am. Ceram. Soc. 83 (2000) 628-634.

[36] Armelao L, Bertagnolli H, Bleiner D, Groenewolt M, Gross S, Krishnan V, et al., Highly dispersed mixed zirconia and hafnia nanoparticles in a silica matrix: first example of a $\mathrm{ZrO}_{2}-$ $\mathrm{HfO}_{2}-\mathrm{SiO}_{2}$ ternary oxide system, Adv. Funct. Mater. 17 (2007) 1671-1681.

[37] Caras CA, Reynard JM, Deuro RE, Bright FV, Link between $\mathrm{O}_{2} \mathrm{SiH}$ infrared band amplitude and porous silicon photoluminescence during ambient $\mathrm{O}_{3}$ oxidation, Appl. Spectrosc. 66 (2012) 951-957.

[38] Sailor MJ. Porous silicon in practice: preparation, characterization and applications, John Wiley \& Sons, Weinheim, 2012.

[39] Neumayer D, Cartier E, Materials characterization of $\mathrm{ZrO}_{2}-\mathrm{SiO}_{2}$ and $\mathrm{HfO}_{2}-\mathrm{SiO}_{2}$ binary oxides deposited by chemical solution deposition, J. Appl. Phys. 90 (2001) 1801-1808.

[40] Kurniawan T, Cheong KY, Razak KA, Lockman Z, Ahmad N, Oxidation of sputtered Zr thin film on Si substrate, J. Mater. Sci. - Mater. Electron. 22 (2011) 143-150.

[41] Bosman HJM, Kruissink EC, Vanderspoel J, Vandenbrink F, Characterization of the Acid Strength of $\mathrm{SiO}_{2}-\mathrm{ZrO}_{2}$ Mixed Oxides, J. Catal. 148 (1994) 660-672.

[42] Tian B, Zhang X, Liu LM, Xu HJ, Anneal effect on multipeak photoluminescence properties of porous silicon pillar arrays, Opt. Commun. 338 (2015) 154-158.

[43] Reynard JM. Porous silicon photoluminescence in the presence of gaseous analytes [Ph.D.]: University at Buffalo; 2015. 
[44] Dohnalova K, Poddubny AN, Prokofiev AA, de Boer WDAM, Umesh CP, Paulusse JMJ, et al., Surface brightens up Si quantum dots: direct bandgap-like size-tunable emission, Light Sci. Appl. 2 (2013) e47.

[45] Kelly MT, Bocarsly $A B$, Effects of $\mathrm{SO}_{2}$ and $\mathrm{I}_{2}$ on the photoluminescence of oxidized porous silicon, Chem. Mater. 9 (1997) 1659-1664. 


\section{Figure Captions}

Figure 1. MOx-pSi fabrication and visual characterization. (a) Overall fabrication protocol. Chemistries at the pSi surface areis shown. (b) ap-pSi after exposure to pH 12 (contrast adjusted).

Figure 2. MOx-pSi SEM, EDS and IR characterization. $\mathrm{ZrO}_{2}-\mathrm{pSi}$ : (a) cross-sectional SEM; (b) EDS spectrum; (c) IR spectrum. $\mathrm{HfO}_{2}$-pSi: (d) cross-sectional SEM; (e) EDS spectrum; (f) IR spectrum.

Figure 3. Typical pH-dependent $\mathrm{ZrO}_{2}-\mathrm{pSi}$ PL results. (a) PL emission spectra (top), normalized PL emission spectra (bottom). (b) pH-dependent intensity response (top), $\mathrm{pH}$-dependent $\lambda e m$, max response (bottom). (c) Consecutive $\mathrm{pH}$-dependent intensity and $\lambda \mathrm{em}$, max response cycles (dashed lines are drawn as a visual guide).

Figure 4. Typical pH-dependent $\mathrm{HfO}_{2}$-pSi PL results. (a) PL emission spectra (top), normalized PL emission spectra (bottom). (b) pH-dependent intensity response (top), pH-dependent $\lambda$ em, max response (bottom). (c) Consecutive $\mathrm{pH}$-dependent intensity and $\lambda \mathrm{em}$, max response cycles (dashed lines are drawn as a visual guide).

Figure 5. Typical photostability results. 


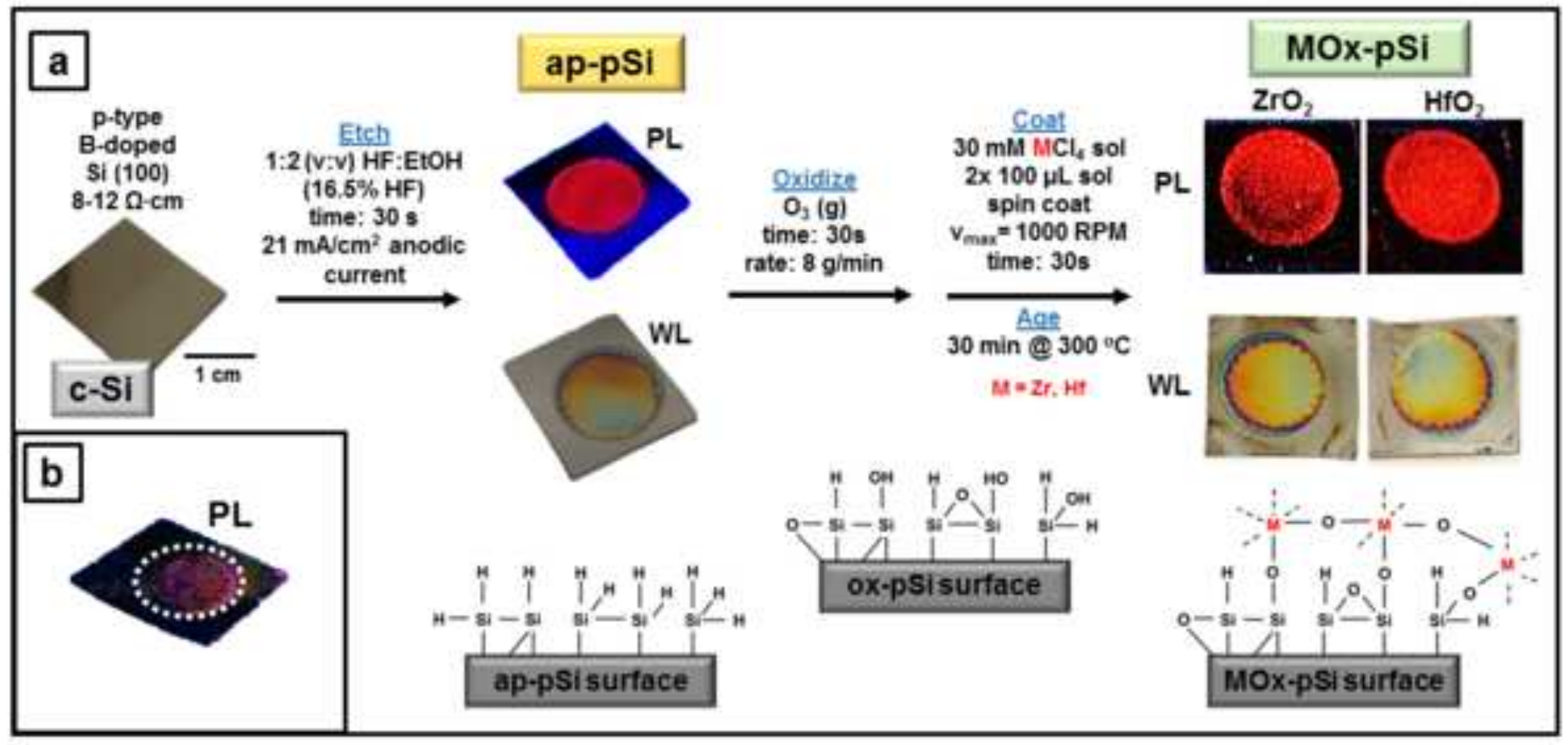



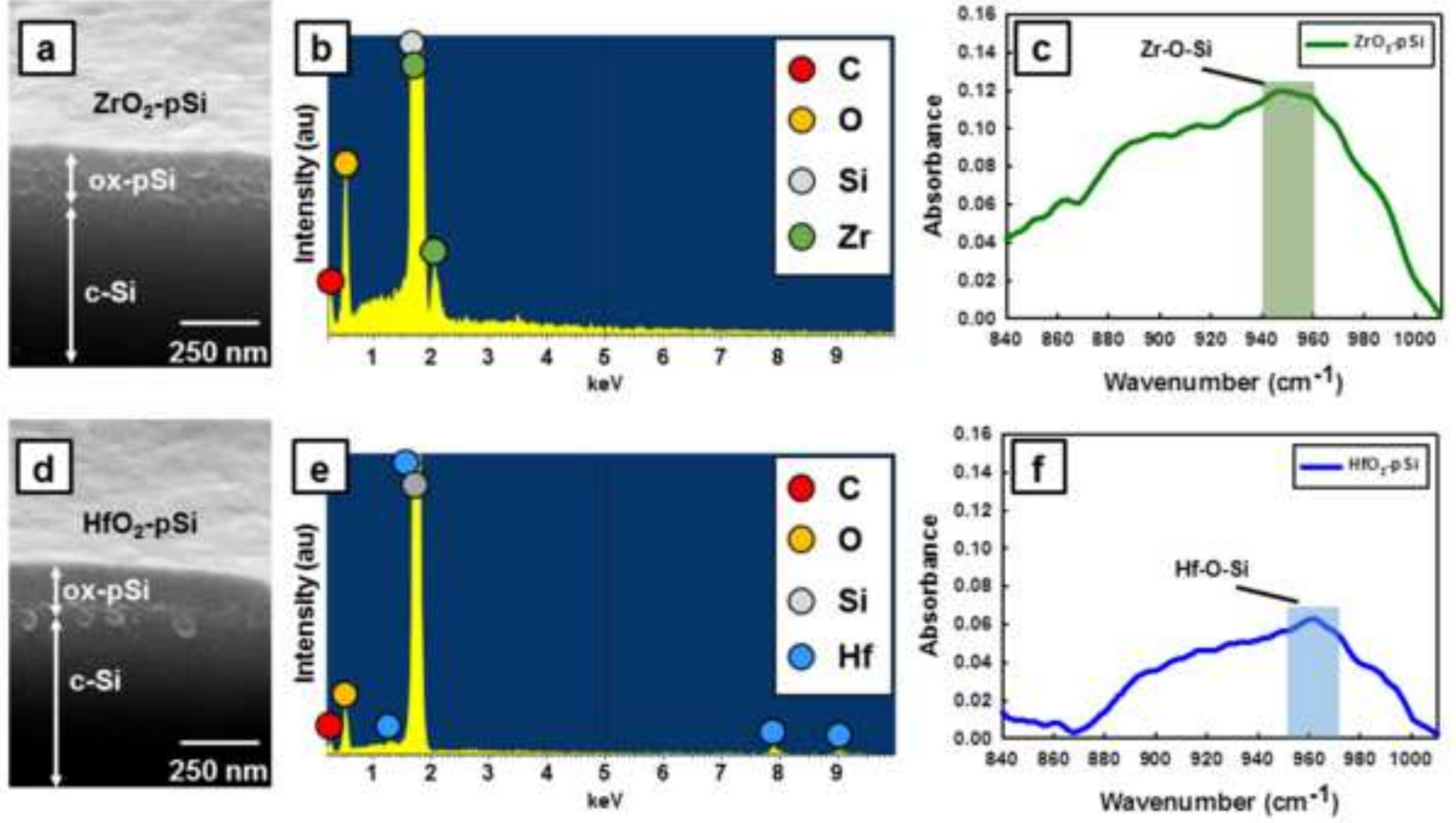

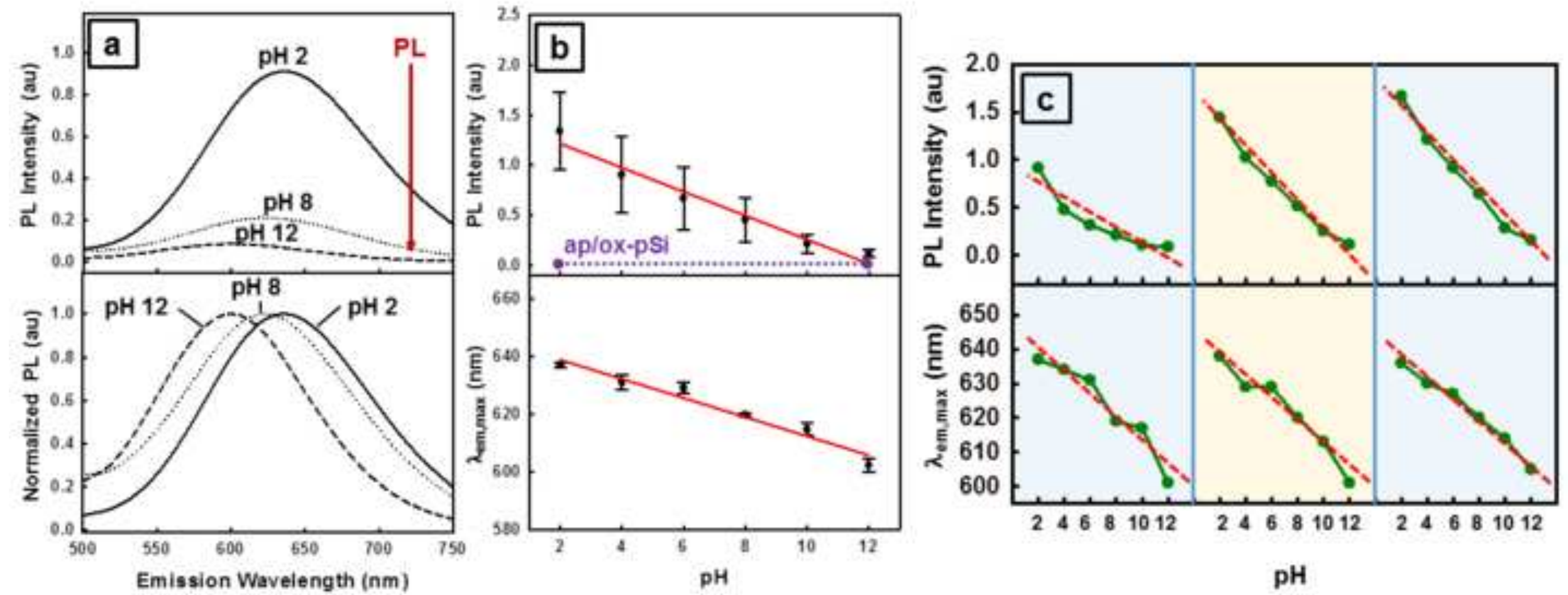

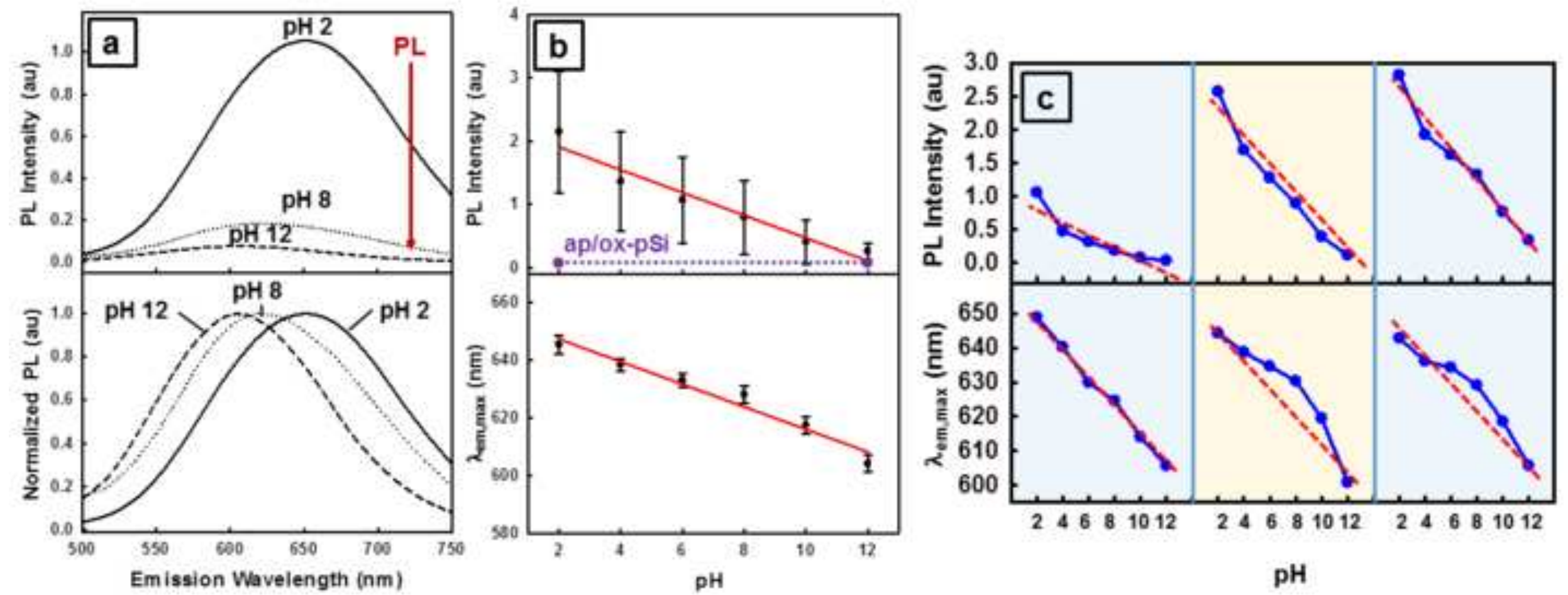


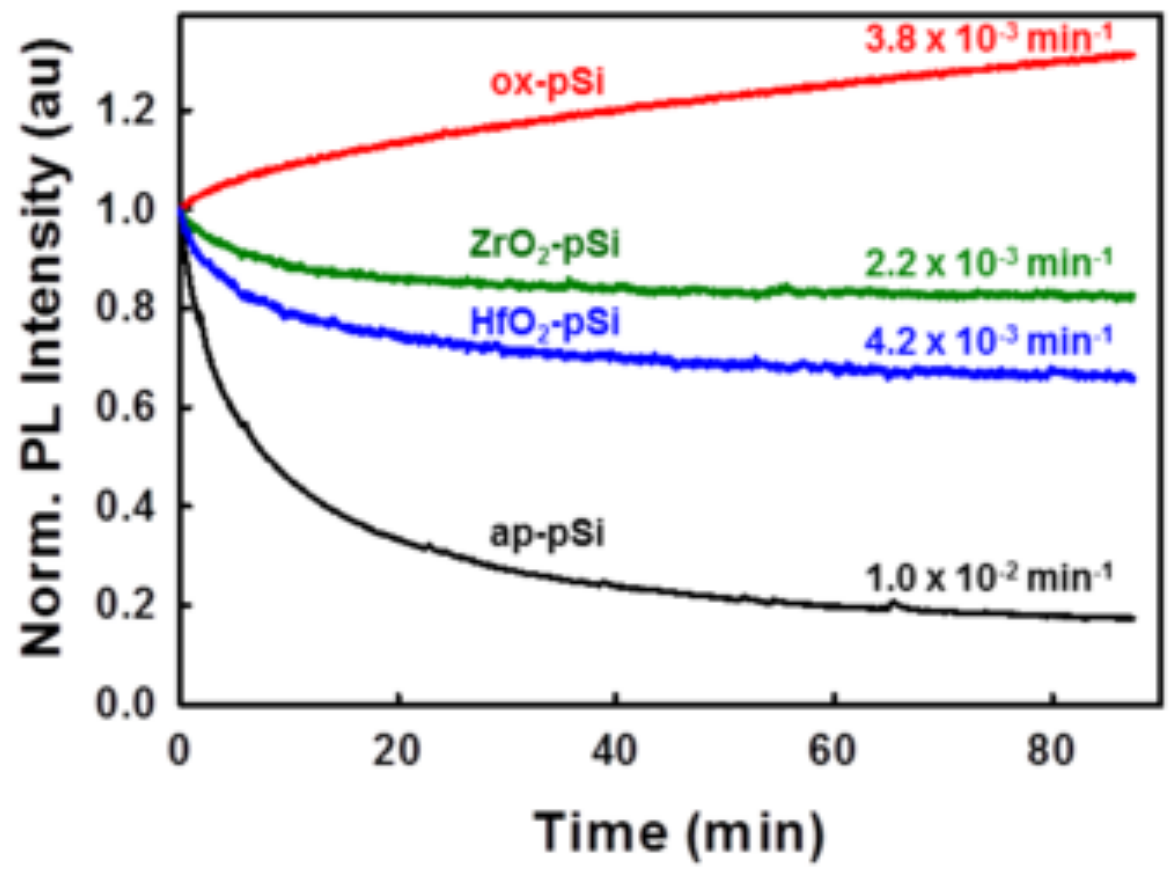




\section{$\mathrm{ZrO}_{2}-\mathrm{pSi}$}
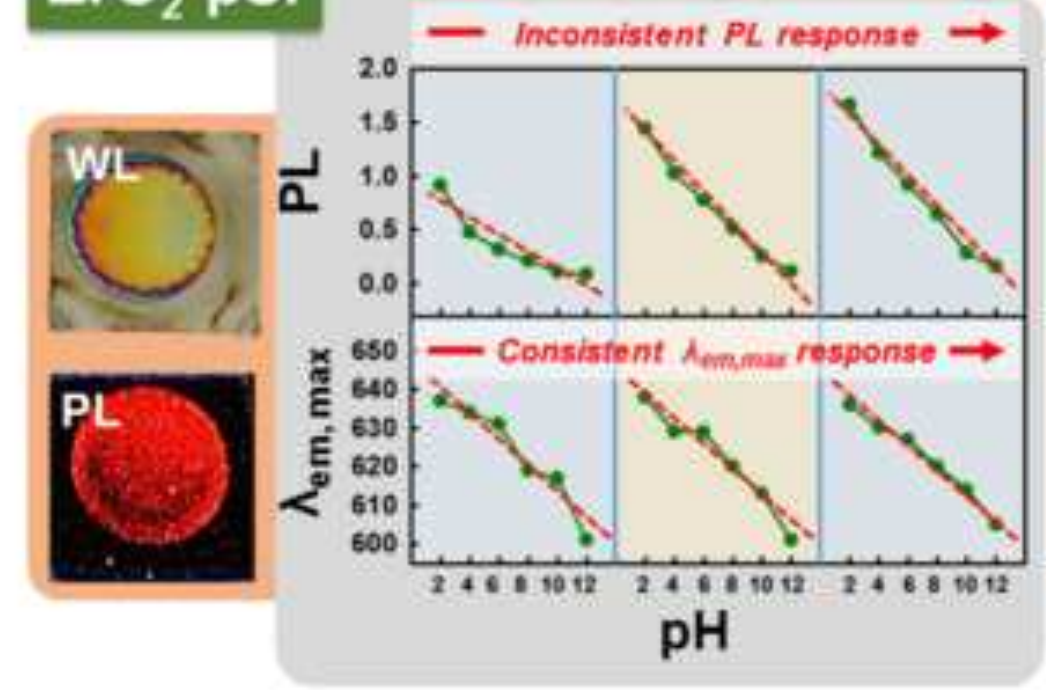

\section{$\mathrm{HFO}_{2}$-pSi}

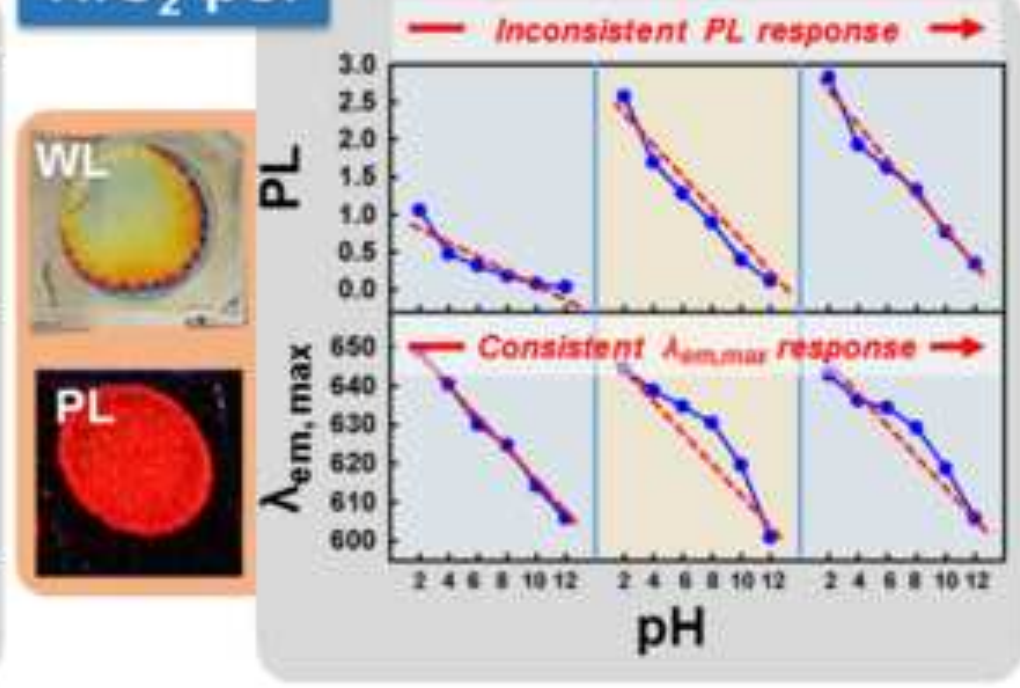

$\mathrm{pH}$ 